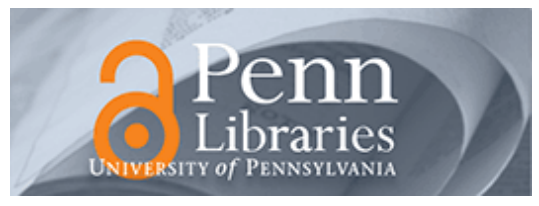

University of Pennsylvania

ScholarlyCommons

Departmental Papers (BE)

Department of Bioengineering

September 2008

\title{
In vitro surface reaction layer formation and dissolution of calcium phosphate cement - bioactive glass composites
}

Changsheng Liu

East China University of Science and Technology

Chien-Wen Chen

University of Pennsylvania

Paul Ducheyne

University of Pennsylvania, ducheyne@seas.upenn.edu

Follow this and additional works at: https://repository.upenn.edu/be_papers

\section{Recommended Citation}

Liu, C., Chen, C., \& Ducheyne, P. (2008). In vitro surface reaction layer formation and dissolution of calcium phosphate cement - bioactive glass composites. Retrieved from https://repository.upenn.edu/

be_papers/125

Postprint version. Published in Biomedical Materials 3, Volume 3, Article 034111, September 2008.

Publisher URL: http://dx.doi.org/10.1088/1748-6041/3/3/034111

This paper is posted at ScholarlyCommons. https://repository.upenn.edu/be_papers/125

For more information, please contact repository@pobox.upenn.edu. 


\title{
In vitro surface reaction layer formation and dissolution of calcium phosphate cement - bioactive glass composites
}

\begin{abstract}
Composites of hydrated calcium phosphate cement (CPC) and bioactive glass (BG) containing Si were immersed in vitro to study the effect of chemical composition on surface reaction layer formation and dissolution/precipitation behavior. The solutions used were $0.05 \mathrm{M}$ tris hydroxymethyl aminomethane $/ \mathrm{HCl}$ (tris buffer), tris buffer supplemented with plasma electrolyte (TE) with $\mathrm{pH} 7.4$ at $37^{\circ} \mathrm{C}$, and this solution complemented with $10 \%$ newborn bovine serum (TES). The post-immersion solutions were analyzed for changes in $\mathrm{Ca}, \mathrm{PO}_{4}$ and $\mathrm{Si}$ concentrations. The reacted surfaces were analyzed using Fourier transform infrared (FTIR), and scanning electron microscopy (SEM) with energy dispersive X-ray analysis (EDX). The sample weight variations after immersion were also determined.

The results showed that the composition of the bioactive composite CPCs greatly affected their behavior in solution and the formation of apatite bioactive surface reaction layers. After immersion in TE solution, $\mathrm{Ca}$ ions were taken up by all samples during the entire immersion duration. Initially, the $\mathrm{P}$ ion concentration increased sharply, and then decreased. This reaction pattern reveals the formation of an amorphous calcium phosphate layer on the surface of these composite calcium phosphate cements. FTIR revealed that the layer was, in fact, poorly crystallized Ca-deficient carbonate apatite. The thickness of the layer was 12-14 $\mu \mathrm{m}$ and was composed of rod-like apatite with directional arrangement. For immersion in TES solution, the $\mathrm{Ca}$ and $\mathrm{Si}$ ion concentrations showed a similar behavior as that in TE, but the release rate of Si ion was higher. FTIR revealed that after TES immersion, not only did the typical, poorly crystallized, Ca-deficient carbonated apatite form, as it did in TE, but that the serum proteins coadsorbed on the surface and thereby affected the surface reaction layer formation. A thinner apatite layer was formed and was composed of a micro-porous layer comprising rounded particles in a glue-like appearing matrix. The addition of BG to the calcium phosphate cements to create composite calcium phosphate cements obviously is at the basis of this altered behavior of the cements. All data combined are useful for the design and optimization of degradable implant materials for use in bone tissue repair and regeneration procedures.
\end{abstract}

\section{Keywords}

calcium phosphate cement, bioactive glass, immersion, apatite, bioactive

\section{Comments}

Postprint version. Published in Biomedical Materials 3, Volume 3, Article 034111, September 2008.

Publisher URL: http://dx.doi.org/10.1088/1748-6041/3/3/034111 


\title{
In vitro surface reaction layer formation and dissolution of calcium phosphate cement - bioactive glass composites
}

\author{
Changsheng Liu ${ }^{1 *}$, Chien-Wen Chen ${ }^{2}$ and Paul Ducheyne ${ }^{2}$ \\ 1 Engineering Research Center for Biomedical Materials of Ministry of Education, East China University of Science and \\ Technology, Shanghai 200237, P. R. China, liucs@ecust.edu.cn \\ 2 Center for Bioactive Materials and Tissue Engineering, Department of Bioengineering, University of Pennsylvania, \\ Philadelphia, Pennsylvania 19104, ducheyne@seas.upenn.edu
}

\begin{abstract}
Composites of hydrated calcium phosphate cement (CPC) and bioactive glass (BG) containing Si were immersed in vitro to study the effect of chemical composition on surface reaction layer formation and dissolution/precipitation behavior. The solutions used were $0.05 \mathrm{M}$ tris hydroxymethyl aminomethane/ $\mathrm{HCl}$ (tris buffer), tris buffer supplemented with plasma electrolyte (TE) with $\mathrm{pH} 7.4$ at $37^{\circ} \mathrm{C}$, and this solution complemented with $10 \%$ newborn bovine serum (TES). The post-immersion solutions were analyzed for changes in $\mathrm{Ca}, \mathrm{PO}_{4}$ and $\mathrm{Si}$ concentrations. The reacted surfaces were analyzed using Fourier transform infrared (FTIR), and scanning electron microscopy (SEM) with energy dispersive X-ray analysis (EDX). The sample weight variations after immersion were also determined.

The results showed that the composition of the bioactive composite CPCs greatly affected their behavior in solution and the formation of apatite bioactive surface reaction layers. After immersion in TE solution, Ca ions were taken up by all samples during the entire immersion duration. Initially, the P ion concentration increased sharply, and then decreased. This reaction pattern reveals the formation of an amorphous calcium phosphate layer on the surface of these composite calcium phosphate cements. FTIR revealed that the layer was, in fact, poorly crystallized Ca-deficient carbonate apatite. The thickness of the layer was $12-14 \mu \mathrm{m}$ and was composed of rod-like apatite with directional arrangement. For immersion in TES solution, the $\mathrm{Ca}$ and $\mathrm{Si}$ ion concentrations showed a similar behavior as that in TE, but the release rate of Si ion was higher. FTIR revealed that after TES immersion, not only did the typical, poorly crystallized, Ca-deficient carbonated apatite form, as it did in TE, but that the serum proteins co-adsorbed on the surface and thereby affected the surface reaction layer formation. A thinner apatite layer was formed and was composed of a micro-porous layer comprising rounded particles in a glue-like appearing matrix. The addition of BG to the calcium phosphate cements to create composite calcium phosphate cements obviously is at the basis of this altered behavior of the cements. All data combined are useful for the design and optimization of degradable implant materials for use in bone tissue repair and regeneration procedures.
\end{abstract}

Keywords: calcium phosphate cement; bioactive glass; immersion; apatite; bioactive

*Corresponding author: Changsheng Liu, E-mail: liucs@ecust.edu.cn 


\section{Introduction}

In recent years, many inorganic bioactive materials have been studied for the repair and filling of bone defects and as scaffolds for tissue engineering. They include calcium phosphate ceramics [1-4], hydroxyapatite (HA) ceramic [5-6], bioactive glass (BG) [7-10] and calcium phosphate cements (CPC) [11-15]. Some of these materials have been used in the clinic with excellent results [16-19]. HA, TCP and BG are usually considered bone bioactive ceramics, implying that they bond to surrounding osseous tissue and enhance bone tissue formation. Analyses of the bone implant interface revealed that the presence or formation of hydroxyapatite in situ is one of the key features of the bonding zone. In addition, it was found that the larger the dissolution rate of the ceramic was, the more pronounced was the enhancement effect on bone tissue growth. Thus, it was established that among bioactive ceramics, dense, stoichiometric hydroxyapatite has a limited reactivity. More reactive calcium phosphate ceramics, such as biphasic calcium-phosphate ceramics consisting of equal amounts of $\beta$-tricalcium phosphate and hydroxyapatite were materials undergoing dissolution and precipitation in vitro. These materials were also found to elicit excellent bone growth in osseous defects in vivo. These biphasic calcium-phosphate ceramics are generally considered to be osteoconductive, all while being adsorbed.

Recently, Ducheyne et al. reported that bioactive glass released $\mathrm{Ca}, \mathrm{P}$, and $\mathrm{Si}$ ions as part of the cascade of reactions that include the calcium phosphate layer formation and the preferential absorption of proteins such as fibronectin [7, 20]. This latter step is an intermediary step preceding osteoblast cell attachment to the material surface. These steps also affect the osteogenic expression of the cells, as it was found that, using MC3T3-E1 cells, the osteoblast phenotype expression increased. Another result was related to the alkaline phosphatase (ALP) activity of marrow stromal cells (MSCs) cultured for 7 days with Ascorbate phosphate, Dexamethasone or BMP-2. The ALP activity of cells cultured on BG was much higher than that of cells just in the culture medium [21]. With the literature being replete with suggestions that material characteristics affect bone tissue formation, we reasoned that we could design a novel bioactive glass material that would still elicit a high cellular response, if we modified BG without affecting its cellular effect arising from its chemical reactivity. We focused on achieving full resorption of the bioceramics, since bioactive glass templates are only slowly replaced by bone tissue [22]. Ideally, this new glassy material could then also be used with or without adding growth factors.

Herein we report on novel material compositions that react to form calcium phosphate in situ. These materials comprise the hydration product of calcium phosphate cement which formed in a hydration environment as basic material, and combine with a kind of materials containing Si. To this first component we add materials containing Si with the goal to increase the cellular response and the expression of bone related genes and proteins [23, 24]. The variation of the concentrations of $\mathrm{Ca}, \mathrm{P}$ and $\mathrm{Si}$ ions in solution and the formation of amorphous calcium phosphate layer on the surface of the materials were investigated by immersing the designed materials in simulated physiological solutions. Two solutions were used: solutions that mimicked the electrolyte composition of interstitial fluid, as well as the same solution with serum proteins added. The materials developed could be used as bone defect filling or as scaffold for bone tissue engineering.

\section{Materials and Methods}

\subsection{Materials preparation}

\subsubsection{Calcium phosphate cement-Bioactive glass composites (CPC-BG)}

Calcium phosphate cements (CPCs) have the composition of tetracalcium phosphate (TECP) and dicalcium phosphate anhydrous (DCPA); hydroxyapatite (HA) was used as the hydration crystal seed. All the calcium phosphates used in the experiment were prepared at the East China University of Science and Technology, and the specific methods can be obtained from relevant literature [25]. The $\mathrm{Ca} / \mathrm{P}$ ratios of $\mathrm{CPCs}$ were 1.67, 1.60, 1.50 and 1.40, which were obtained by changing the ratio of TECP and DCPA, and were coded as $\mathrm{CPC}_{1.67}, \mathrm{CPC}_{1.60}, \mathrm{CPC}_{1.50}, \mathrm{CPC}_{1.40}$. The silicon of the materials comes from the addition of bioactive glass (BG) $45 \mathrm{~S} 5$ granules ( $\mathrm{Wt} \%: 45 \% \mathrm{SiO}_{2}, 24.5 \% \mathrm{Na}_{2} \mathrm{O}, 24.5 \% \mathrm{CaO}$ and $6 \% \mathrm{P}_{2} \mathrm{O}_{5}$ ). The size range as

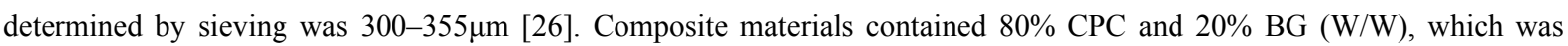


coded as $\mathrm{CPC}_{1.67} \mathrm{BG}$ for the $\mathrm{Ca} / \mathrm{P}$ being 1.67 sample. The composite powder $(0.3 \mathrm{~g})$ was mixed with deionized water $(0.075$ $\mathrm{ml}$ ) at a powder to liquid ratio of 4 (weight/volume) to form slurry. This was placed into a plastic mold (4 mm diameter $\mathrm{x}$ $5 \mathrm{~mm}$ height). The top surface of the mold was tightly covered with a plastic film held in place by a ' $\mathrm{C}$ ' clamp and stored at $37^{\circ} \mathrm{C}$ in a $100 \%$ humidity box for hydration during 48 hours, at which time the hardened composite materials were obtained.

2.1.2. Immersion solution: The following solutions were used for the immersion experiments: $0.05 \mathrm{M}$ tris hydroxymethyl aminomethane $/ \mathrm{HCl}$ (tris buffer and coded as T; from Sigma, St. Louis, MO), tris buffer complemented with plasma electrolyte ( $\mathrm{pH} 7.4$ at $37^{\circ} \mathrm{C}$; coded as TE), and tris with plasma electrolyte and $10 \%$ newborn bovine serum (coded as TES).

2.2. In vitro testing

\subsubsection{Immersion procedures}

The composite specimens were immersed in solution at $37^{\circ} \mathrm{C}$. The $\mathrm{pH}$ of the solution stayed at about 7.4 throughout the experiments. Since the $\mathrm{pH}$ of tris buffer is temperature sensitive, all the testing solutions were pre-warmed to $37^{\circ} \mathrm{C}$ prior to immersion. The vials with immersed samples were placed on an orbital shaker maintained at $100 \mathrm{rpm}$ in a humidified atmosphere containing $5 \% \mathrm{CO}_{2}$. The immersion experiments were conducted in triplicate at a $0.5 \mathrm{mg} / \mathrm{mL}$ ratio of materials weight to solution volume. The incubation time varied from 1 day to 7 days, and some immersions were extended to 14 days. After immersion, the samples were rinsed with ethanol, dried, and stored in a desiccator until the time of analysis.

The samples were immersed either integrally (i.e. no solution exchange) or differentially (i.e. with solution exchange). An integral immersion experiment determines product released by sequential measurement of of the dissolution products accumulated into the immersion solution.. This way one obtains an integral dissolution rate. In a differential immersion experiment, the solution is exchanged and renewed every day such that the dissolution rate is determined anew from each smapling point: this way, one determines a differential dissolution rate. In the differential mode, the solutions were exchanged at 3, 6, 10, and $24 \mathrm{~h}$, and then every day. In the differential immersion mode, $\mathrm{Si}, \mathrm{Ca}$ and $\mathrm{P}$ saturation in solution is prevented.

2.2.2. Determination of ion concentrations:

The post-immersion and control solutions (solution before immersion) were analyzed for $\mathrm{Si}$ and $\mathrm{Ca}$ ion. concentrations (i.e. [Si] and [Ca]) using atomic absorption spectrophotometry (AAS 5100, Perkin-Elmer, Norwalk, CT). P ion concentrations (i.e. $[\mathrm{P}]$ ) were measured colorimetrically (molybdenum yellow, $400 \mathrm{~nm}$ ) using UV-visible spectrophotometry (Ultraspec Plus, Pharmacia LKB).

\subsection{Material characterization}

\subsubsection{Weight variation study:}

After 48 hours of hydration, but before the immersion experiment, all the samples were placed in an oven at $45^{\circ} \mathrm{C}$ to dry for $24 \mathrm{~h}$, when there was no more change in weight. The weight of every individual sample was recorded as $\mathrm{W}_{0}$. Following the immersion, the samples were rinsed with ethanol, dried in an oven at $45^{\circ} \mathrm{C}$ for $24 \mathrm{~h}$, and weighted as $\mathrm{W}_{1}$. The difference between $\mathrm{W}_{1}$ and $\mathrm{W}_{0}$ was the weight change.

2.3.2. Chemical and microstructural surface characterization:

Following the weight measurement, the samples were stored in a desiccator, and the compositional and structural changes on the reacted surfaces were determined using Fourier transform infrared spectroscopical analysis (FTIR, 5DXC, Nicolet, Madison, Wisconsin) in the diffuse reflectance mode.

After FTIR analysis, the samples were processed for scanning electron microscopy (SEM, JEOL- 6400, Kyoto, Japan), energy dispersive X-ray analysis (EDX, Kevex, San Carlos, CA) to determine compositional and morphological changes. The depth profiles of the surface layers and the lateral variations in the surface composition could be identified. Morphologic changes are viewed either on the surface of the samples, or on cross-sections of the coatings formed during immersion experiments. Samples for analysis were coated with a thin film of carbon. Quantitative SEM/EDX analysis was performed on non-coated samples. 


\section{Results and discussion}

\subsection{Variation in TE solution}

3.1.1 Change of ion concentrations in TE solution

After differential immersion in TE solution (which is a method to mimic the condition of body fluid in vivo as ions can be eliminated by circulation), Ca ions were taken up by all samples, as is shown by the decrease of [Ca] in solution during the entire duration of immersion (Fig. 1). The result for P ion was more complex (Fig. 2). Initially, all solution concentrations increased sharply, and then decreased rapidly due to P-uptake associated with the formation of amorphous calcium phosphate layer on the surface of the materials (shown below). That is to say that in the TE solution after one day's immersion, the solution was supersaturated, and apparently there was a driving force to forming apatite instead of dissolving the sample. All the samples showed a similar behavior, regardless their $\mathrm{Ca} / \mathrm{P}$ ratio. The variation of [Si] was quite different (Fig. 3), showing a continuous increase over 7 days. That means that Si dissolved from all the samples over the 7 day immersion period. In addition, the amount of $\mathrm{Si}$ ions releases from $\mathrm{CPC}_{1.5} \mathrm{BG}$ was higher than that from $\mathrm{CPC}_{1.67} \mathrm{BG}$. Based on all data, it can be concluded that the dissolution of the samples and the formation of the amorphous calcium phosphate layers on their surfaces occurred simultaneously.

As for the control samples, namely bioactive glass by itself, Fig. 4 (differential immersion) shows that [Ca] increased initially, and then gradually decreased, while [P] decreased until about day 3, from which time on it stayed about constant. At 6 days, the $[\mathrm{Ca}]$ and $[\mathrm{P}]$ remained constant, indicating continuing uptake of same quantities for both ions. For the cumulative result (Fig. 5), calcium was released, while phosphorus was removed from solution. The [Si] profile was yet different, as $\mathrm{Si}$ ion was always released during immersion, with an initial release rate higher than later on. This indicated that initially, the bioactive glass was dissolved, and then the dissolution and precipitation occurred at same time. With the formation of apatite on the surface of granules, the dissolution rate decreased, with these processes merging to equilibrium. The samples immersed in the TE solution integrally showed accumulation of [Ca] and [P] (Fig. 7): for calcium at once ([Ca] decreased to 60-65 mg/L and then stayed constant), while [P] increased at first, and then dropped off. Silicon, in contrast, was continuously released from the sample (Fig. 8) .

\subsubsection{Surface analysis}

FTIR analysis revealed that the spectra of all the samples after immersion in TE for 14 days showed changes in their appearance in comparison to the spectra of samples before immersion (Fig. 9). Absorption bands located at 1080 and 470 $\mathrm{cm}^{-1}$ before immersion (see Fig. 9A) was typical for non-reacted BG45S5 and was due to the Si-O group vibration. The FTIR spectra after immersion (see Fig. 9B) indicated that this phase is typical for poorly crystallized carbonate apatite, which showed the appearance of the bands, located at $870 \mathrm{~cm}^{-1}$ (C-O bond) and $960 \mathrm{~cm}^{-1}$ (P-O symmetric stretch, characteristic of HA). The presence of this kind of crystalline apatite layer at the surface was confirmed by FTIR on all substrates (Fig. 9B).

SEM examination (Fig. 10) revealed that the surface of the samples was fully and uniformly covered by fine, densely packed calcium phosphate precipitates. Cracks can be seen which result from the drying process. This is yet another proof for the formation of a surface layer with properties different from the parent glass, as cracking is not observed on starting samples. The thickness of this layer for $\mathrm{CPC}_{1.67} \mathrm{BG}$ was $13.68 \mu \mathrm{m}$ (Fig. 11), and $\mathrm{CPC}_{1.50} \mathrm{BG}$ was $12.77 \mu \mathrm{m}$. The surface reaction layers were composed of rod-like apatite with directional arrangement as formed during immersion (Fig. 12). Both the samples $\mathrm{CPC}_{1.67} \mathrm{BG}$ and $\mathrm{CPC}_{1.50} \mathrm{BG}$ showed a similar crystalline morphology. This structure was revealed by ion beam bombardment during SEM observation.

The EDX spectrum (Fig. 13) indicated that the surface was a calcium phosphate with a $\mathrm{Ca} / \mathrm{P}$ ratio of about 1.51 . It also contained $\mathrm{Si}$, and further also some $\mathrm{Na}, \mathrm{Mg}$ ions coming from the TE solution. Thus, during immersion, the bioactive composite calcium phosphate cement dissolved and a new surface formed by precipitation and transformation reactions leading to a poorly crystallized, Ca-deficient carbonated apatite. Such result is compatible with supersaturation conditions of the various ions in solution.

3.1.3 Weight variation 
The weight variation of the samples is shown in Fig. 14. It follows that the weight of all samples, either pure CPC or CPC with BG, increased after immersion in TE solution for two weeks. This increase was larger with higher $\mathrm{Ca} / \mathrm{P}$ ratio, suggesting that a higher $\mathrm{Ca} / \mathrm{P}$ ratio resulted in a thicker layer formation. This result is consistent with the data in Fig. 11. Meanwhile, those samples containing bioactive glass had a thinner layer than those without BG, which is related to the fact that the samples with BG dissolved more easily, therefore overall had a lesser increase in weight.

3.2 Variation in TES solution

3.2.1 Change of ion concentrations in TES solution

Upon immersion in the TES solution, we focused on the $[\mathrm{Ca}]$ and [Si] variations. After immersion in TES with solution exchange, the $[\mathrm{Ca}]$ decreased for all the samples over the entire immersion duration (Fig. 15). Initially (within 1 day), all the samples behaved similarly. Later on there were some differences, albeit not remarkable, and very similar to those in the TE solution. The cumulative Si release variations are shown in Fig. 16. Again, as for immersion in TE, there is a continuous increase of [Si] in solution over 7 days. The cumulative amount of $\mathrm{Si}$ in solution for $\mathrm{CPC}_{1.67} \mathrm{BG}$ in TES solution was higher than that of the same sample in TE solution, and the cumulative amount for $\mathrm{CPC}_{1.67} \mathrm{BG}$ in TE solution was higher than that the sample of $\mathrm{CPC}_{1.50}$ in TE solution. This means that when the samples are immersed in TES, they dissolve faster than in TE solution. This is due to serum proteins being incorporated in the precipitated surface layer and the fact that this layer then allows diffusion more easily [8].

The samples immersed in the TES solution integrally showed an accumulation of Ca ions on the surface (Fig. 17). The [Ca] decreased faster in TES solution than that in TE solution. There were no differences in uptake between the samples immersed in TES, with and without BG.

3.2.2 Surface analysis after immersion in TES solution

FTIR analysis revealed that the spectra of all the samples after immersion in TES for 7 days (see Fig. 18) showed changes in their appearance in comparison to the spectra of samples before immersion (Fig. 9A). Absorption bands located at $870 \mathrm{~cm}^{-1}$ (C-O bond) and $960 \mathrm{~cm}^{-1}$ (P-O symmetric stretch, characteristic of HA), which indicated that this phase is typical for poorly crystallized carbonate apatite, and is similar to those in TE solution. Moreover, bands located at 1510 and 1447 $\mathrm{cm}^{-1}$ also appeared which can be assigned to N-H and C-N (Amide II) bonds in proteins [27]. The appearance of these protein bands confirmed that serum proteins were adsorbed onto the surface. Meanwhile, the spectra for $\mathrm{CPC}_{1.67} \mathrm{BG}$ and $\mathrm{CPC}_{1.50} \mathrm{BG}$ showed some peaks before immersion in the range from 1000 to $1100 \mathrm{~cm}^{-1}$, thus revealing residual TECP or unreacted DCPA.

SEM examination (Fig. 19) revealed that the surface of the samples was fully and uniformly covered by calcium phosphate precipitates with small pores. No cracking occurred after the drying process, which is different from the result in TE solution, which revealed a fine, densely packed layer (Fig. 10). The present layer was composed of rounded particles embedded in a glue-like, dense substance. The surface layer, however, was not fully dense as there were micropores in the layer.

The EDX spectrum indicated that the surface was a calcium phosphate with a $\mathrm{Ca} / \mathrm{P}$ ratio of about 1.33 , lower than that formed in TE solution. It also contained $\mathrm{Si}$, and some $\mathrm{Na}, \mathrm{Mg}$ ions from TES solution. Clearly, the serum proteins present in the TES solution took part in and affected the formation of the poorly crystallized, Ca-deficient carbonated apatite.

3.2.3 Weight variation after immersion in TES solution

The weight variation of the samples after immersion in TES for 1 week is shown in Fig. 20. It follows that there was little variation to the weight of the sample with $\mathrm{BG}$, with either a $\mathrm{Ca} / \mathrm{P}$ ratio equal 1.67 , or equal to 1.5 . This result is irrespective of the surface layer formation. It demonstrates that the layer is very thin, and that the dissolution of the sample with BG is faster in TES solution that that in TE solution. In fact, apparent weight changes are due to a combined variation of dissolution of the matrix and formation of the apatite layer. In comparison to the data in Fig. 14, the same samples experienced less of a weight change when immersed in TES than in TE. By creating calcium phosphate cements in a 
composite form, the addition of the BG obviously affects the reactions in solution and the surface layer formation reaction, certainly in the presence of serum proteins.

\section{Conclusions}

The addition of bioactive glass $45 \mathrm{~S} 5$ to calcium phosphate cement, which leads to the formation of a bioactive composite CPC, greatly affects its behavior in solution. This influences the surface reactions and the formation of a bioactive apatite surface layer. When the bioactive composite cement is immersed in TE solution, the [Ca] decreased during the entire immersion duration, but the $[\mathrm{P}]$ first increased sharply, and then decreased rapidly. These reactions lead to the formation of a poorly crystallized carbonate apatite surface layer with the distinguishing feature of having rod-like calcium phosphate crystals. When immersed in TES solution, the $[\mathrm{Ca}]$ and $[\mathrm{Si}]$ in solution varied very similarly as to the behavior observed for immersion in TE, but release rates (of $\mathrm{Si}$ ) were higher. FTIR revealed that after TES immersion, the typical poorly-crystallized, Ca-deficient carbonated apatite formed as it did in TE, but serum proteins were adsorbed onto the surface and influenced the mineralization of this thinner apatite layer. After immersion in TES this layer was composed of rounded particles embedded in a glue-like, dense substance. The apparent weight change arising from oppositely acting effects, namely matrix dissolution and apatite layer formation, indicated that the same samples had less weight change when immersed in TES solution than that in TE solution. The formation of composite materials with BG, obviously affected this result prominently. The work presented here has the potential to open up the field for the exploration of bioactive composite calcium phosphate cements. We also suggest that this study may lay the foundation for the further understanding of mechanism of degradability of composite calcium phosphate cements after implantation. Future investigations will be concerned with the cell response to these novel bioactive composite cements for bone defect repair and study the effect as tissue engineering scaffolds for the stimulation of tissue repair and regeneration.

\section{Acknowledgements}

The authors appreciate financial support from the National Science Fund for Distinguished Young Scholars of China (Grant No.20425621) and Major Program of National Natural Science Foundation of China (No. 50732002).

\section{References}

1. Papadimitropoulos A, Mastrogiacomo M, Peyrin F, et al 2007 Kinetics of in vivo bone deposition by bone marrow stromal cells within a resorbable porous calcium phosphate scaffold: An X-ray computed microtomography study Biotech. Bioeng. 98 (1) $271-281$

2. da Silva RV, Bertran CA, Kawachi EY, et al 2007 Repair of cranial bone defects with calcium phosphate ceramic implant or autogenous bone graft J. Craniofac. Surg. 18 (2) 281-286

3. Arinzeh TL, Tran T, Mcalary J, et al 2005 A comparative study of biphasic calcium phosphate ceramics for human mesenchymal stem-cell-induced bone formation Biomaterials 26 (17) 3631-3638

4. Kamakura S, Sasano Y, Nakajo S, et al 2001 Implantation of octacalcium phosphate combined with transforming growth factor-b1 enhances bone repair as well as resorption of the implant in rat skull defects J. Biomed. Mater. Res. 57 175-182

5. Ni SY, Chang J, Chou L, et al 2007 Comparison of osteoblast-like cell responses to calcium silicate and tricalcium phosphate ceramics in vitro J. Biomed. Mater. Res. Part B-Appl. Biomater. 80B (1) 174-183

6. Yuan H, van Blitterswijk CA, de Groot K, et al 2006 A comparison of bone formation in biphasic calcium phosphate (BCP) and hydroxyapatite (HA) implanted in muscle and bone of dogs at different time periods J. Biomed. Mater. Res. Part A 78A (1) $139-147$

7. Ducheyne P and Qiu QQ 1999 Bioactive ceramics: the effect of surface reactivity on bone formation and bone cell function Biomaterials 20 2287-2303

8. Radin S, Ducheyne P, Falaize S and Hammond A 2000 In vitro transformation of bioactive glass granules into Ca-P shells 
9. Xynos ID, Hukkanen MVJ, Batten JJ, et al 2000 Bioglass 45S5 stimulates osteoblast turnover and enhances bone formation in vitro: implications and applications for bone tissue engineering Calcif. Tissue Int. 67 321-329

10. Reilly GC, Radin S, Chen AT, et al 2007 Differential alkaline phosphatase responses of rat and human bone marrow derived mesenchymal stem cells to 45S5 bloactive glass Biomaterials 28 (28) 4091-4097

11. Brown WE and Chow LC 1986 A new calcium phosphate, water-setting cement Cements Research Progress ed P W Brown (Westerville, OH: American Ceramic Society) pp 352-79

12. Chow LC 1991 Development of self-setting calcium phosphate cement The Centen. Memor. Issue Ceram. Soc. Jap. 99(10) 954-64

13. Guo H, Wei J and Liu CS 2006 Development of a degradable cement of calcium phosphate and calcium sulfate composite for bone reconstruction Biomed. Mater. 1 (4) 193-197

14. Guo H, Wei J, Yuan Y and Liu CS 2007 Development of calcium silicate/calcium phosphate cement for bone regeneration Biomed. Mater. 2 (3) S153-S159

15. Xu HHK, Burguera EF and Carey LE 2007 Strong, macroporous, and in situ-setting calcium phosphate cement-layered structures Biomaterials 28 (26) 3786-3796

16. Chen TY, Li L, Li XD, Wang WB and Chen ZW 1999 Clinical application of autosolidification calcium phosphate cement to repair bone defects, a preliminary report Chin. J. Traumatol. 15(3) 184-6

17. Tien YC, Chih TT, Lin JH, Ju CP and Lin SD 2004 Augmentation of tendon-bone healing by the use of calcium-phosphate cement J. Bone Joint Surg. Br. 86(7) 1072-6

18. Hak DJ, 2007 The use of osteoconductive bone graft substitutes in orthopaedic trauma J. Am. Acad. Orthopad. Surg. 15 (9) $525-536$

19. Lozano-Calderon S, Moore M, Liebman M, et al 2007 Distal radius osteotomy in the elderly patient using angular stable implants and Norian bone cement J. Hand. Surg-Am. 32A (7) 976-983

20. Lee MH, Ducheyne P, Lynch L, et al 2006 Effect of biomaterial surface properties on fibronectin-alpha(5)beta(1) integrin interaction and cellular attachment Biomaterials 27 (9) 1907-1916

21. Radin S, Reilly G, Bhargave G, Leboy PS and Ducheyne P 2005 Osteogenic effects of bioactive glass on bone marrow stromal cells J. Biomed. Mater. Res. 73A 21 - 29

22. Porter AE, Patel N, Skepper JN, et al 2003 Comparison of in vivo dissolution processes in hydroxyapatite and silicon-substituted hydroxyapatite bioceramics Biomaterials 24 4609-4620

23.Xynos ID, Edgar AJ, Buttery LDK, Hench LL, et al 2001 Gene-expression profiling of human osteoblasts following treatment with the ionic products of Bioglasst 45S5 dissolution J. Biomed. Mater. Res. 55 151-157

24. Knabe C, Berger G, Gildenhaar R, et al 2004 Effect of rapidly resorbable calcium phosphates and a calcium phosphate bone cement on the expression of bonerelated genes and proteins in vitro J. Biomed. Mater. Res. 69A 145-154

25. Liu CS, Shao HF, Chen FY and Zheng HY 2006 Rheological properties of concentrated aqueous injectable calcium phosphate cement slurry Biomaterials 27 5003-5013

26. Radin S, Ducheyne P, Rothman B and Conti A 1997 The effect of in vitro modeling conditions on the surface reactions of bioactive glass J. Biomed. Mater. Res. 37 363-375

27. Sauer GR and Wuthier RE 1988 Fourier transform infrared characterization of mineral phases formed during induction of mineralization by collagenase-released matrix vesicles in vitro J. Biol. Chem. 263 13718-13724 


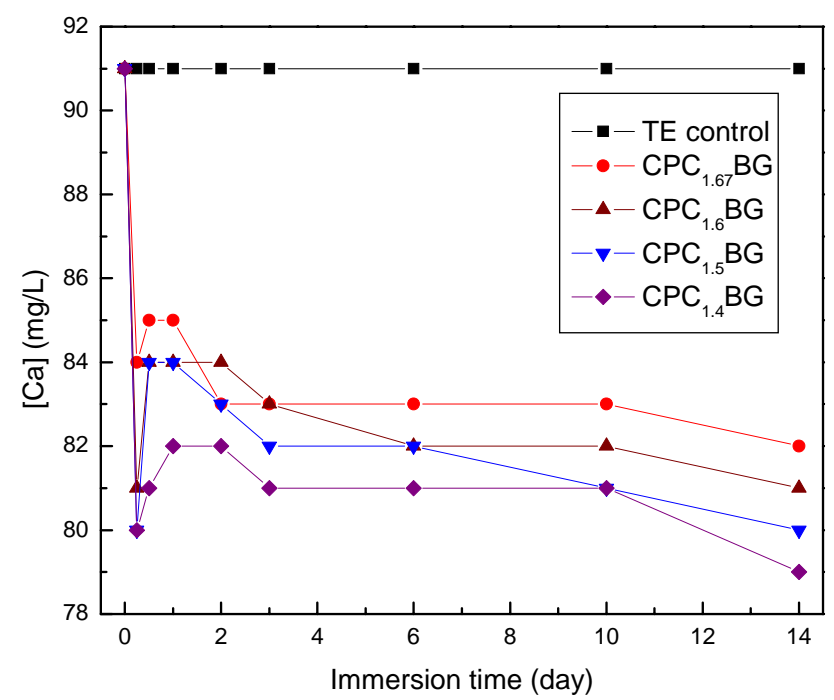

Fig. 1 Variation of [Ca] during differential immersion in TE solution for cement-bioactive glass composite samples

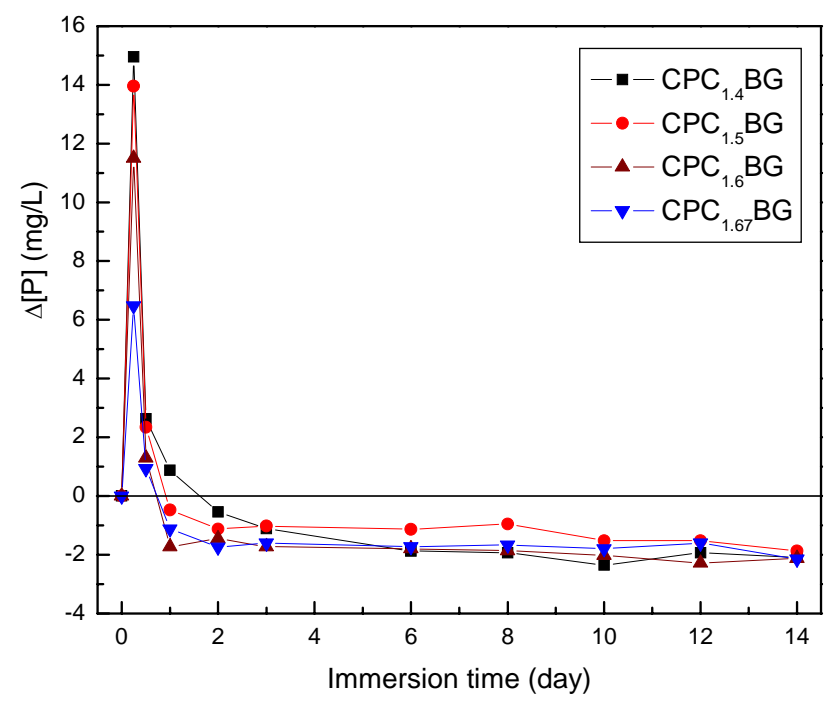

Fig 2 Variation of $[\mathrm{P}]$ during differential immersion in TE solution for cement-bioactive glass composite samples Initial [P] was $29.54 \mathrm{mg} / \mathrm{L}$. 


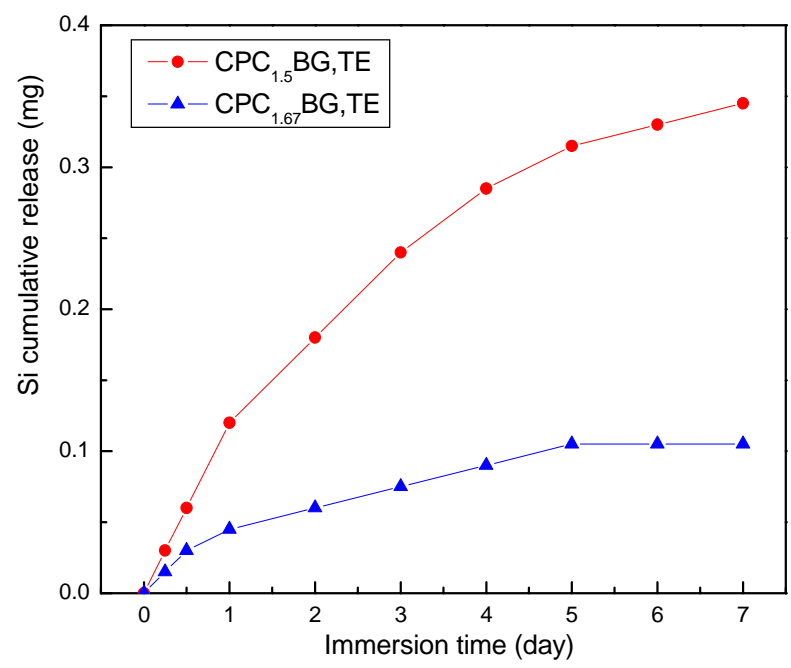

Fig. 3 Variation of Si during differential immersion in TE solution for cement-bioactive glass composite samples

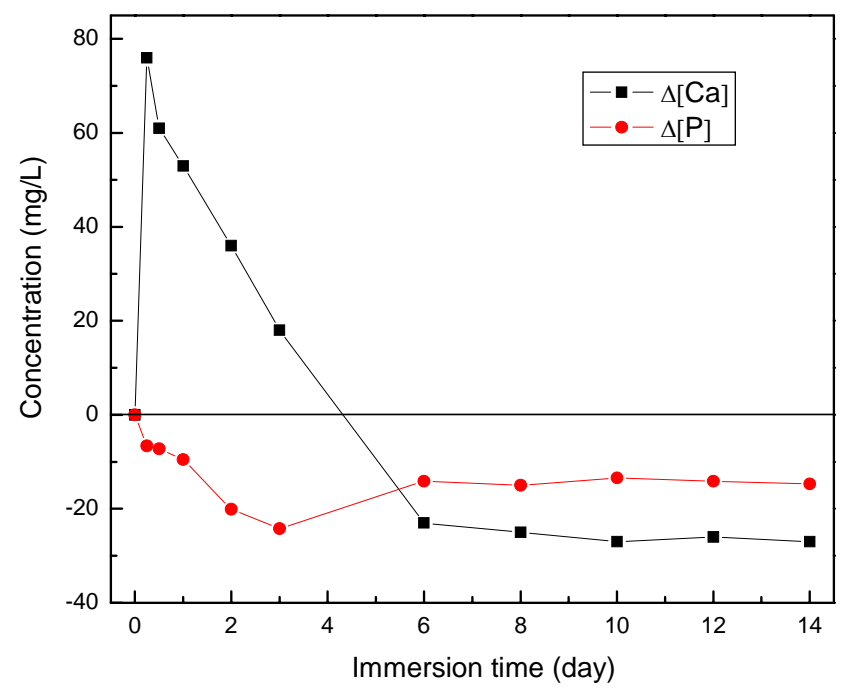

Fig. 4 Variation of $[\mathrm{Ca}]$ and $[\mathrm{P}]$ change during differential immersion in TE solution for bioactive glass Initial [Ca] was $91 \mathrm{mg} / \mathrm{L}$, and initial [P] was $29.54 \mathrm{mg} / \mathrm{L}$. 


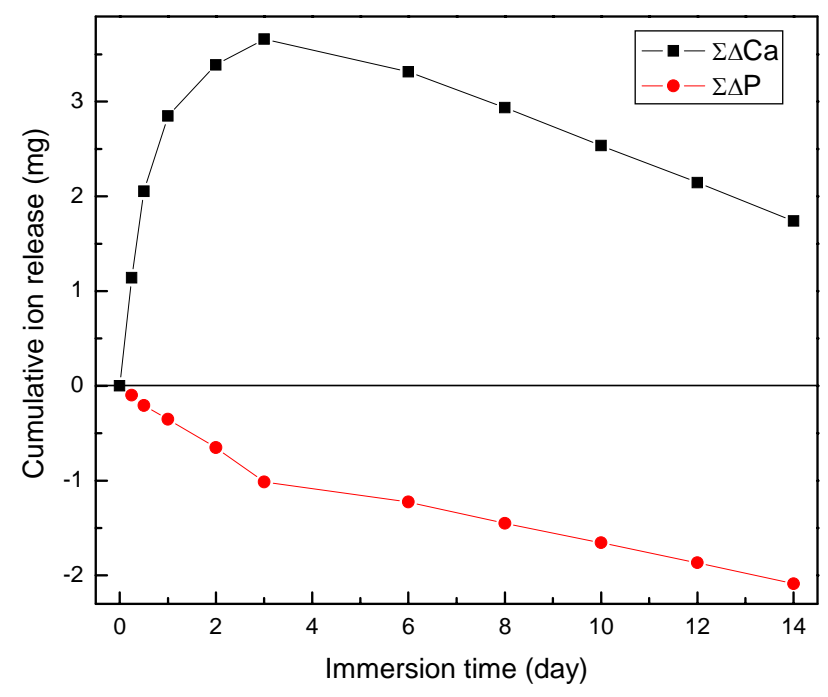

Fig. 5 Cumulative changes in the $\mathrm{Ca}$ and $\mathrm{P}$ over the control level (TE solution) during differential immersion in TE solution for bioactive glass

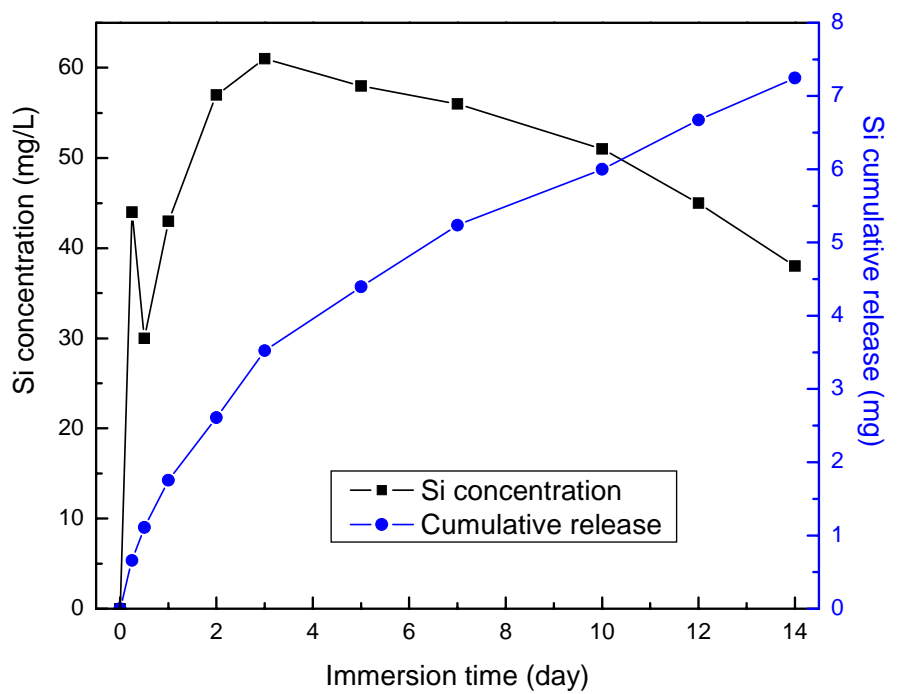

Fig. 6 Si concentration and cumulative changes with time during differential immersion in TE solution for bioactive glass 


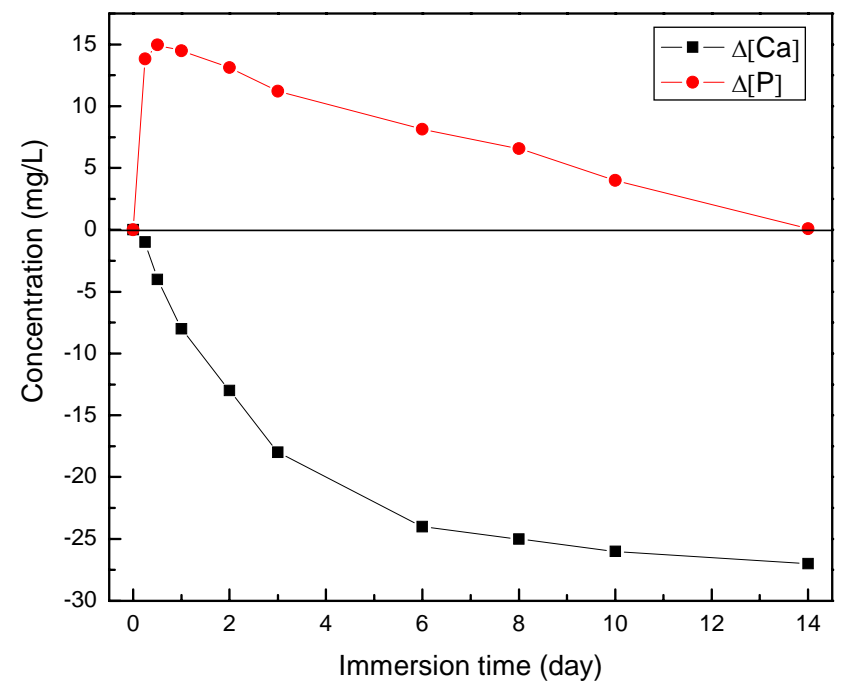

Fig. 7 Variation of $[\mathrm{Ca}]$ or $[\mathrm{P}]$ change during integral immersion in $\mathrm{TE}$ solution for $\mathrm{CPC}_{1.5} \mathrm{BG}$ Initial [Ca] was $91 \mathrm{mg} / \mathrm{L}$, and initial [P] was $29.54 \mathrm{mg} / \mathrm{L}$.

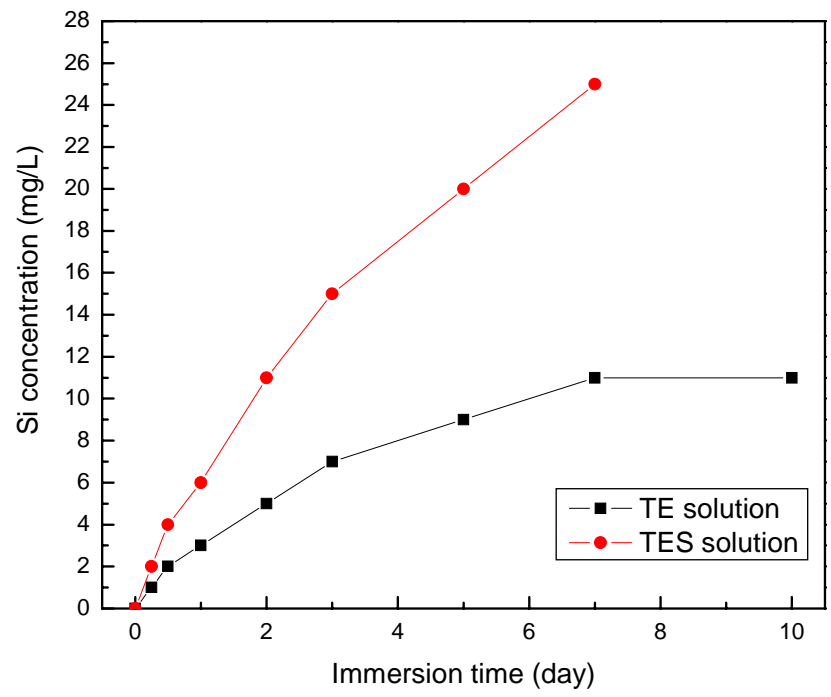

Fig. 8 Variation of [Si] during integral immersion in the TE and TES solution for $\mathrm{CPC}_{1.5} \mathrm{BG}$ 


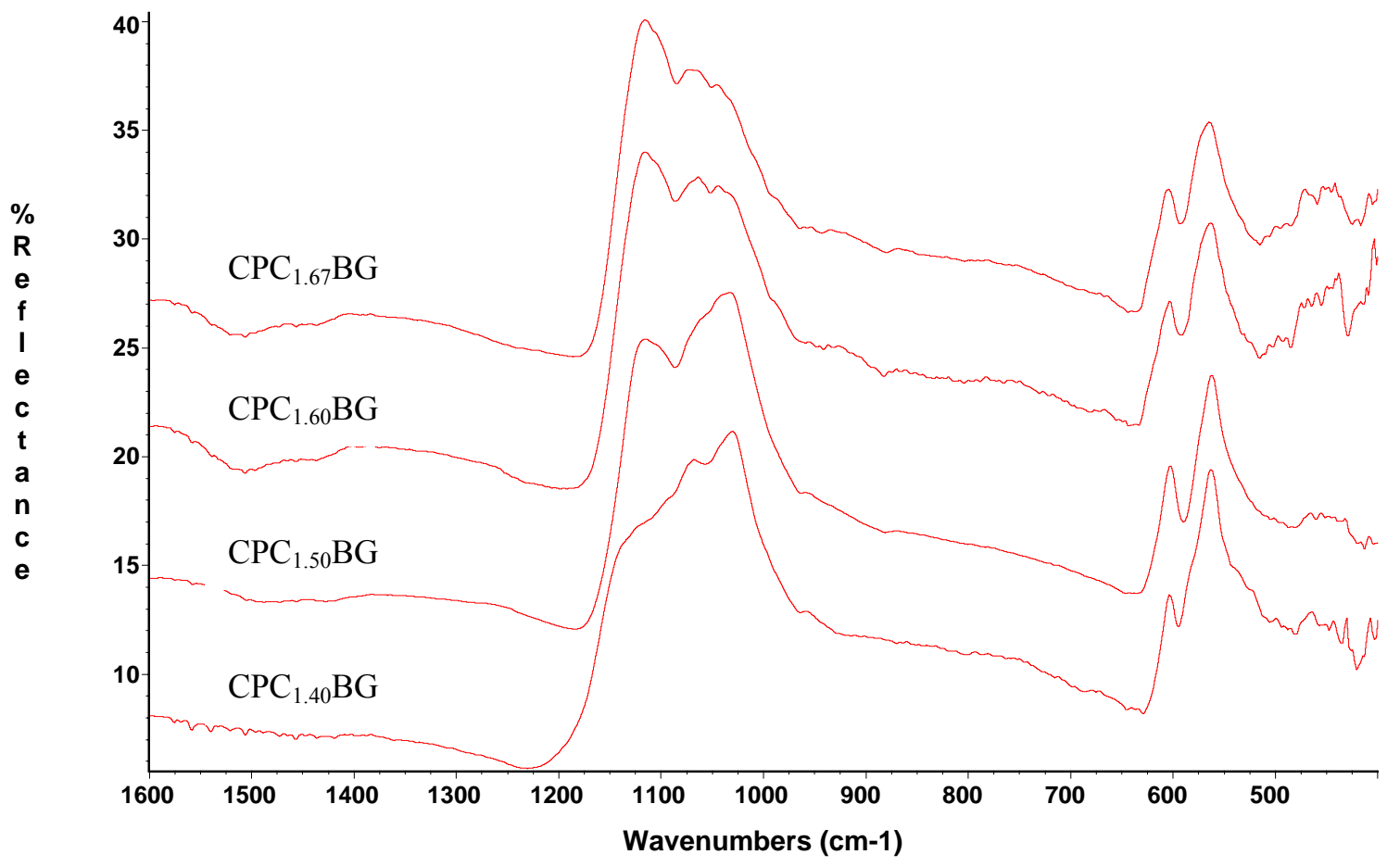

A. after hydration but before immersion

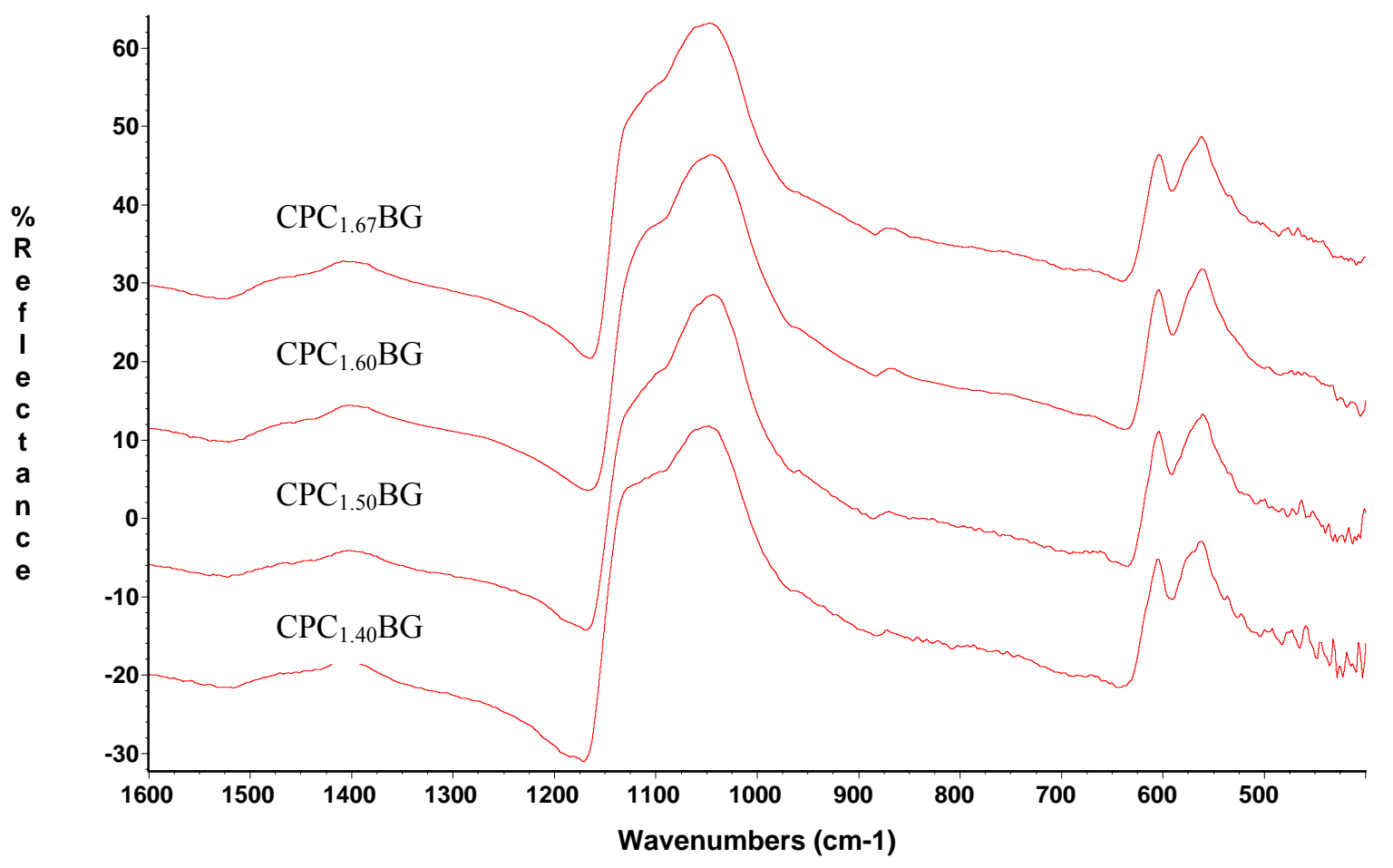

B. after immersion in TE solution for two weeks

Fig. 9 The FTIR spectra of cement-bioactive glass composite samples before and after differential immersion 


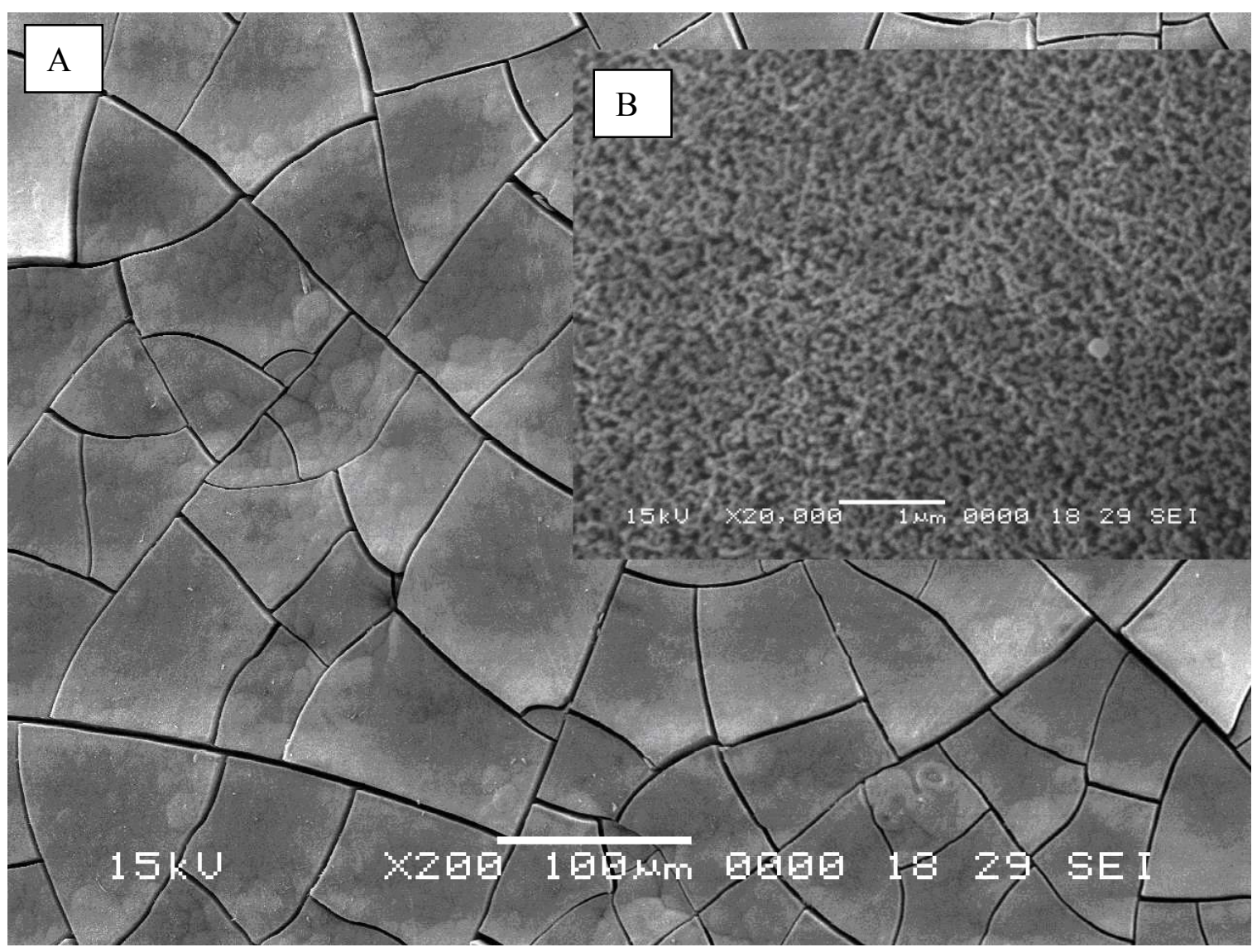

Fig. 10 SEM images of the surface of $\mathrm{CPC}_{1.5} \mathrm{BG}$ after differential immersion in TE solution for 14 days. $\mathrm{B}$ is the magnification of $\mathrm{A}$. 

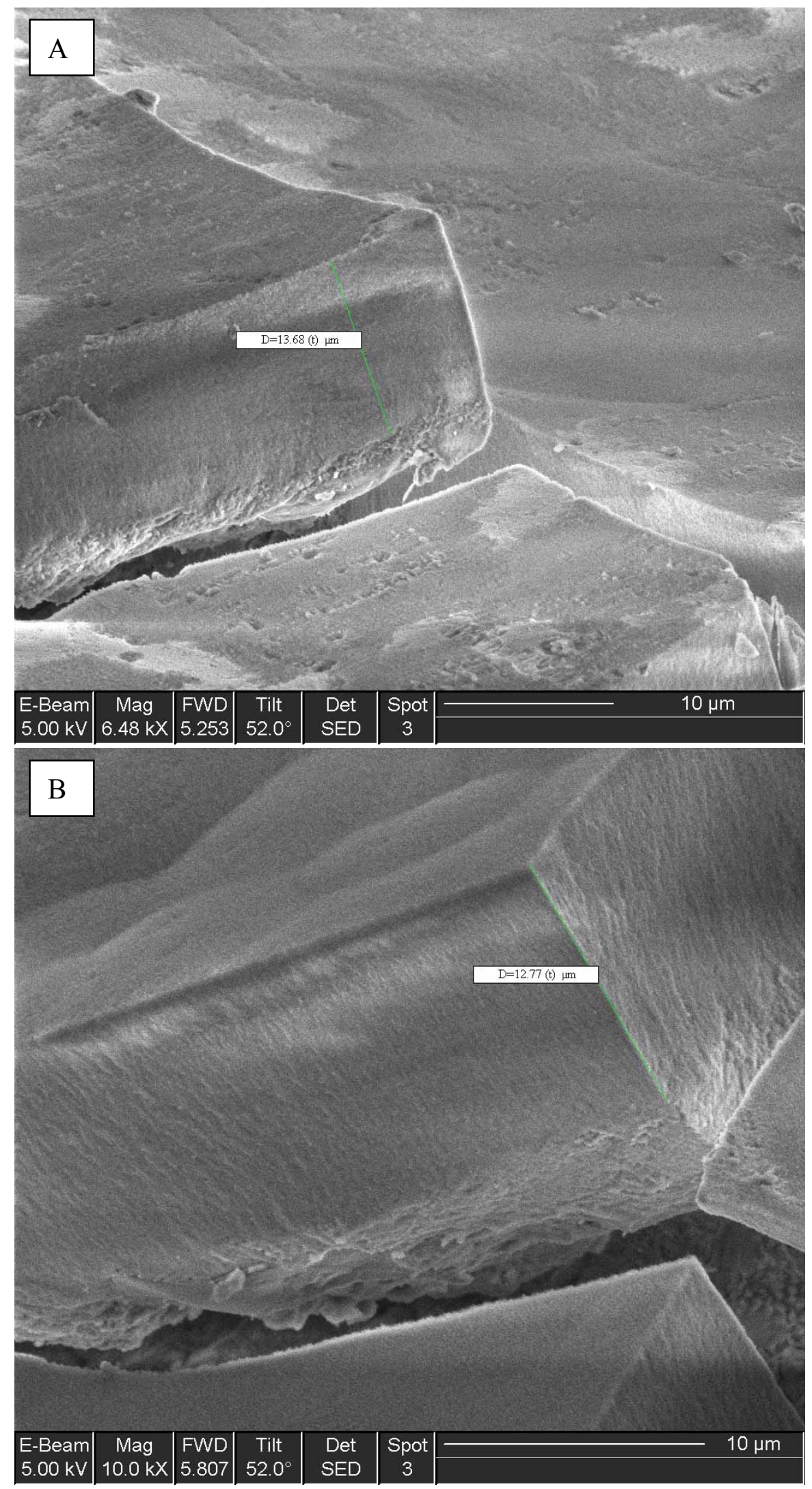

Fig. 11 SEM images of the thickness of the surface layers for cement-bioactive glass composite samples after differential immersion in TE solution for 14 days. A: thickness of $\mathrm{CPC}_{1.67} \mathrm{BG}, \mathrm{B}$ : thickness of $\mathrm{CPC}_{1.5} \mathrm{BG}$ 

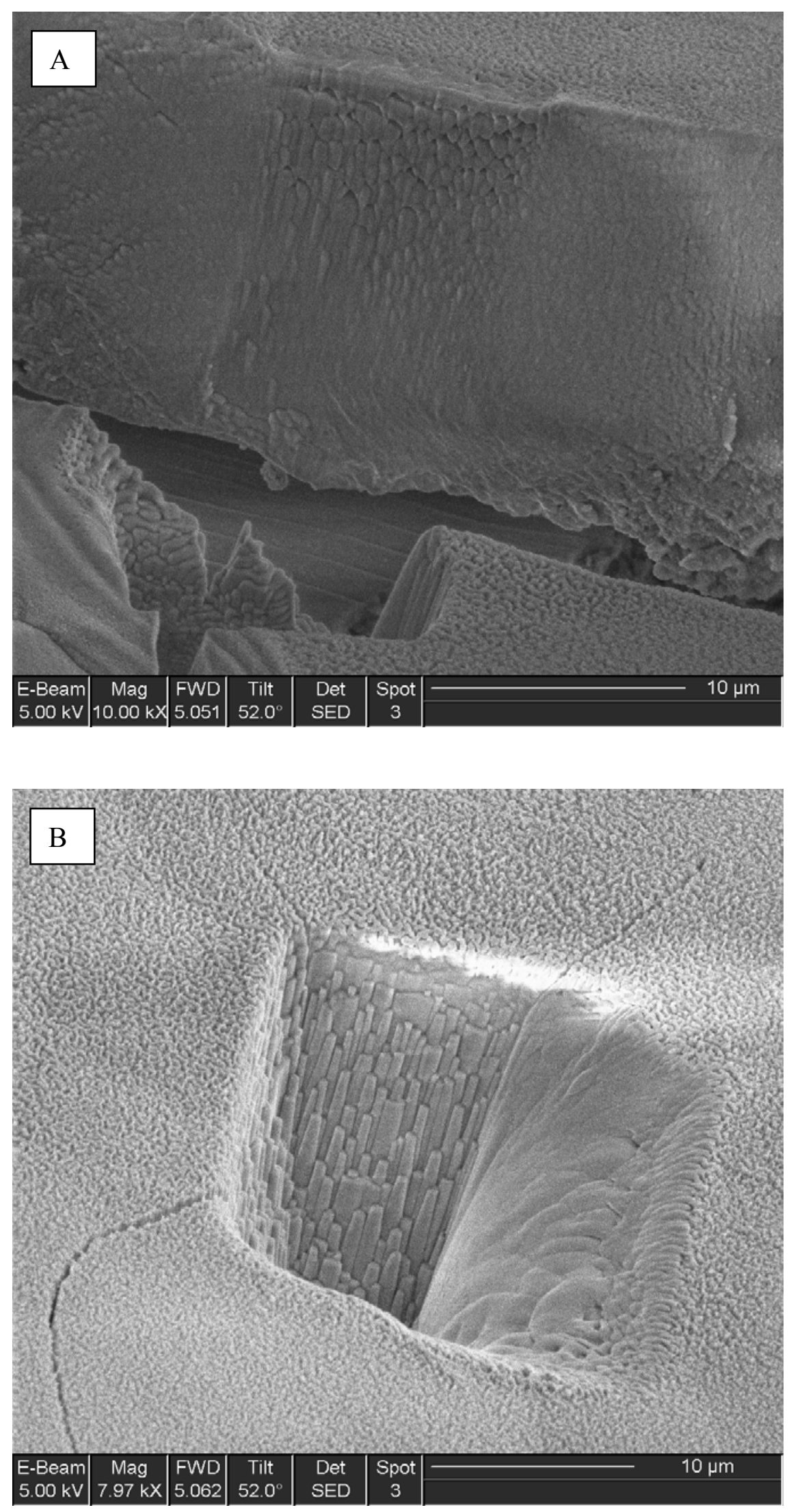

Fig. 12 SEM micrographs of the layer of $\mathrm{CPC}_{1.5} \mathrm{BG}$, revealing the morphology of the crystal after ion beam bombardment 


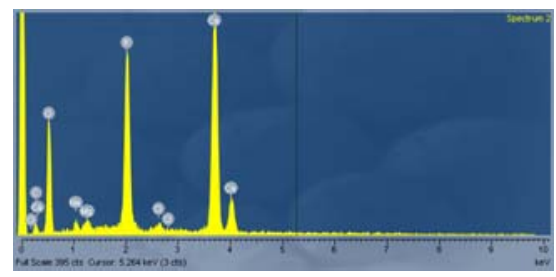

Fig. 13 EDX spectrum of the surface of $\mathrm{CPC}_{1.50} \mathrm{BG}$ after differential immersion in TE solution for 14 days

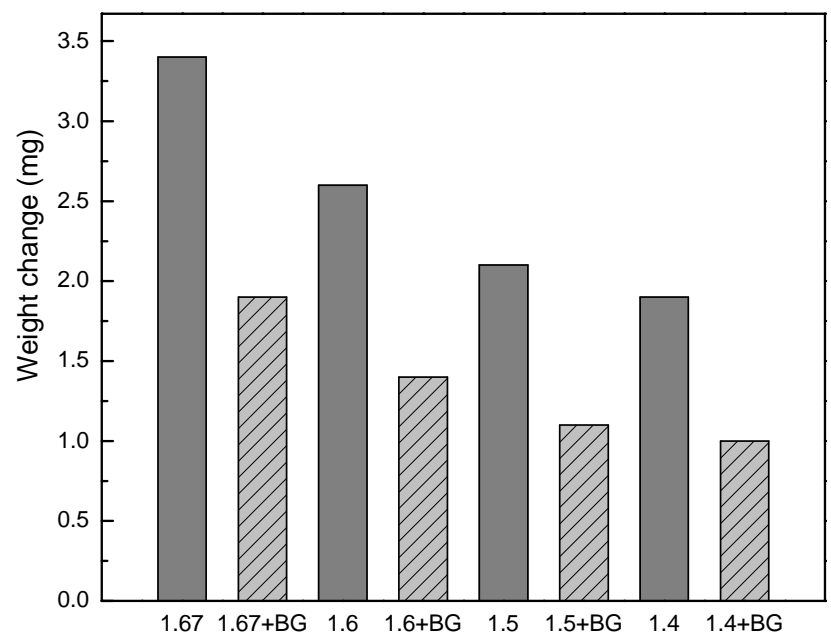

Fig. 14 Weight changes after differential immersion in TE for 14 days In the figure, 1.67 means $\mathrm{CPC}_{1.67}, 1.67+\mathrm{BG}$ means $\mathrm{CPC}_{1.67} \mathrm{BG}$, and so on 


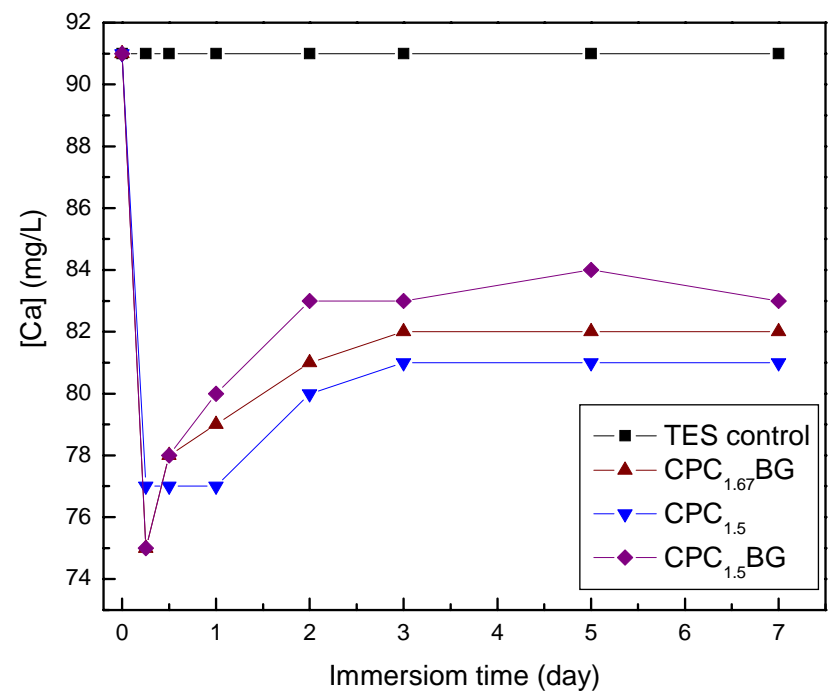

Fig. 15 Variation of [Ca] during differential immersion in TES solution for cement-bioactive glass composite samples

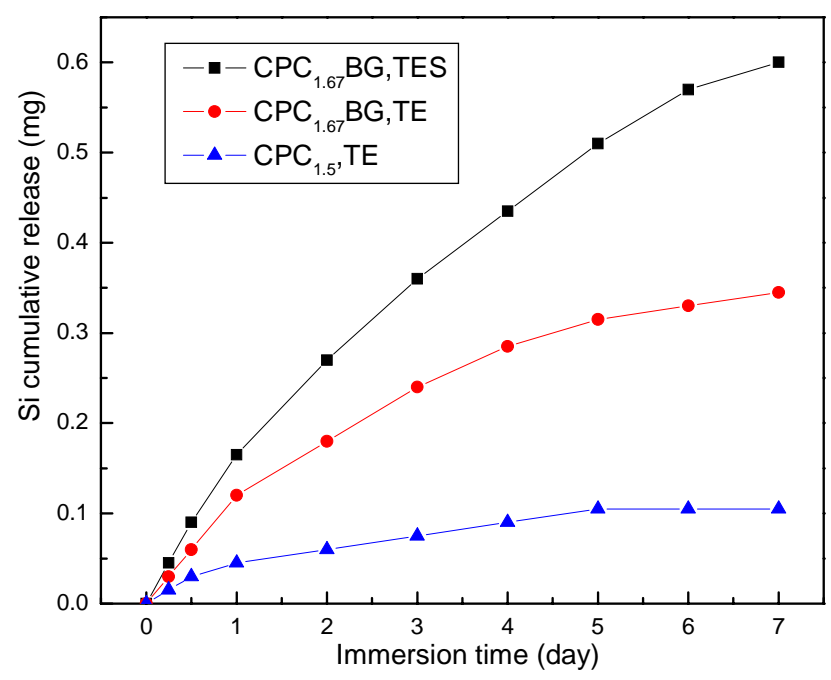

Fig. 16 Variation of cumulative Si release during differential immersion in TES solution for cement-bioactive glass composite samples compared with in TE solution 


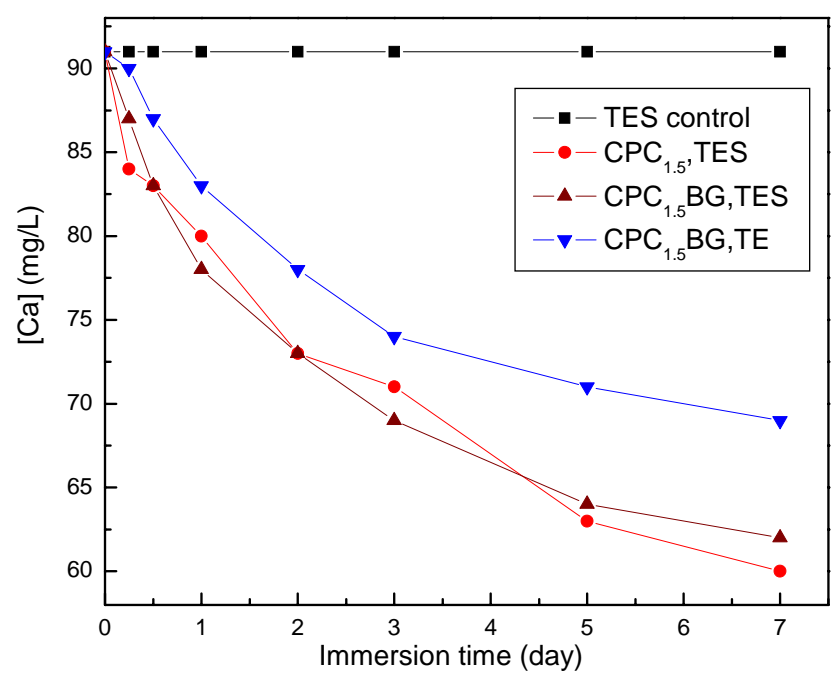

Fig. 17 Variation of [Ca] during integral immersion in TE or TES solution for cement-bioactive glass composite samples 


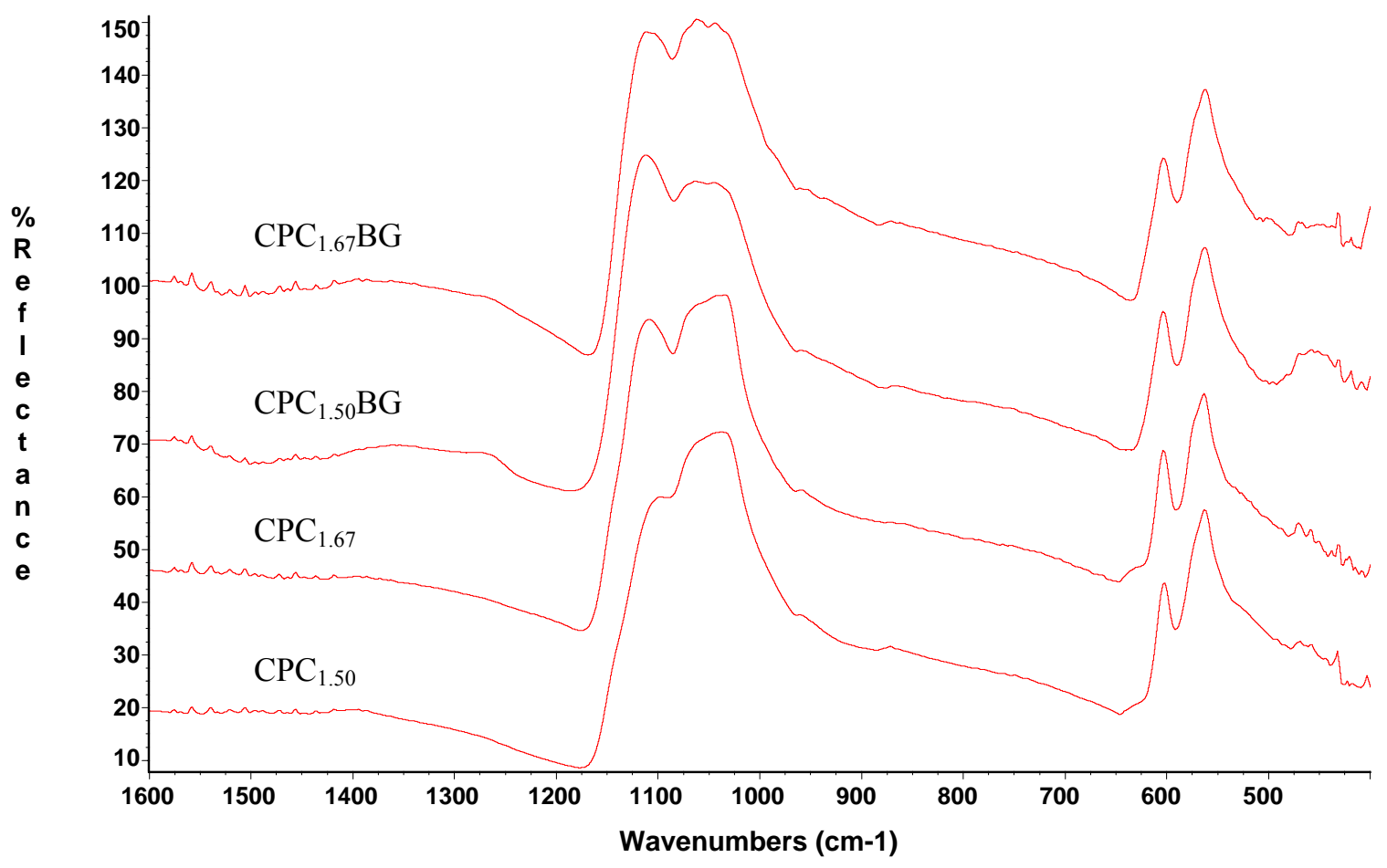

Fig. 18 The FTIR spectra of the cement-bioactive glass composite samples after differential immersion in TES solution for 7 days

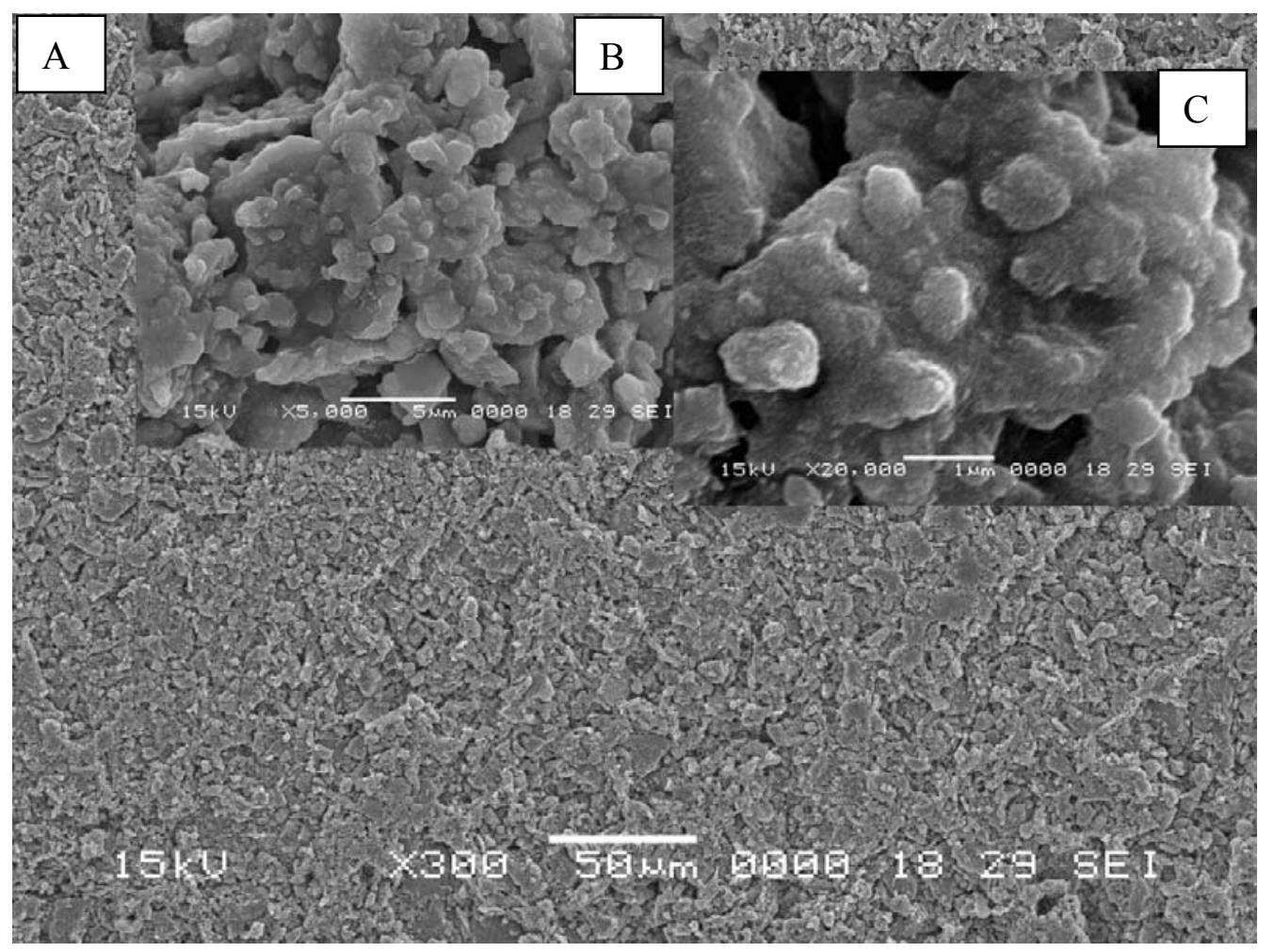

Fig. 19 SEM images of the surface of $\mathrm{CPC}_{1.50} \mathrm{BG}$ after differential immersion in TES solution for 7 days. $\mathrm{B}$ is the magnification of $\mathrm{A}$, and $\mathrm{C}$ is the magnification of $\mathrm{B}$. 


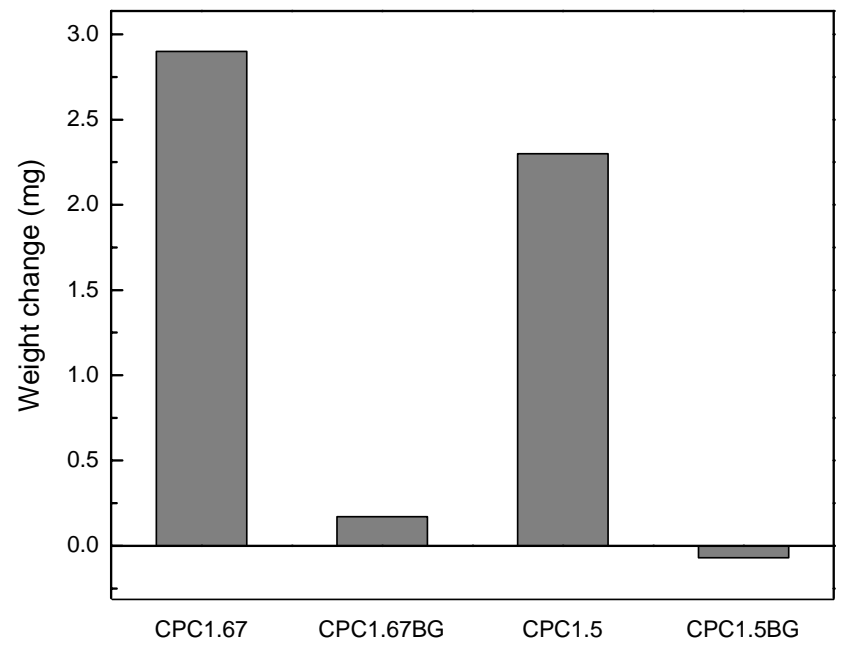

Fig. 20 Weight changes after differential immersion in TES for 7 days 